\title{
Profil Pemahaman Konsep Nilai Tempat Ditinjau dari KEMAMPUAN AWAL MaTEMATIKA PADA SISWA KELAS III SDN 133 TAKALALA SOPPENG
}

\author{
Profile of Place Value Concept Understanding Based on The initial \\ Mathematical SKILlS IN III ClasS OF 133 ${ }^{\mathrm{TH}}$ PRIMARY SCHOOL OF TAKalala \\ SOPPENG
}

\author{
Andi Yunarni Yusri ${ }^{1}$ dan Miftah Sari² \\ 1,2 Pendidikan Matematika, Pascasarjana Universitas Negeri Makassar \\ 1 yunarniyusri@gmail.com
}

\begin{abstract}
Abstrak
Tujuan dari penelitian ini adalah untuk menggambarkan pemahaman siswa dari notasi aljabar pada melalui kemampuan. Pemahaman dalam penelitian ini berarti kemampuan untuk menerjemahkan (terjemahan), kemampuan untuk menafsirkan (interpretasi), dan kemampuan untuk ekstrapolasi. Penelitian ini merupakan penelitian kualitatif. Subyek penelitian ini adalah empat siswa kelas lima di SD, terdiri dari dua siswa dengan kemampuan verbal yang tinggi disebut sebagai subyek tinggi verbal (SVT), 1 siswa dengan mata pelajaran lisan menengah (SVS), dan satu siswa dengan mata pelajaran lisan rendah ( SVR). Fokus penelitian ini adalah untuk mendeskripsikan pemahaman siswa tentang notasi aljabar berdasarkan kemampuan verbal mereka dalam terjemahan, interpretasi, dan ekstrapolasi. Data dikumpulkan dengan melakukan wawancara berdasarkan tes-dengan subyek penelitian. The dara penelitian divalidasi dengan melakukan metode triangulasi item, yaitu menggunakan pertanyaan wawancara utama sebagai pertanyaan dinyatakan dalam tPNA. Data penelitian dianalisis oleh (a) mempelajari subyek data dan diwawancarai Membandingkan data untuk Mendapatkan satu valid, (b) melakukan reduksi data dengan membuat abstraksi, (c) mengklasifikasikan dan mengidentifikasi data adalah untuk menarik kesimpulan. Hasil penelitian menunjukkan bahwa (1) pemahaman notasi aljabar dari pelajaran lisan tinggi (SVT): (a) pemahaman tentang simbol termasuk dalam pemahaman yang menerjemahkan (terjemahan), (b) memahami konsep simbol tapi Blum adalah mampu pemadam antara simbol dan variabel, (c) mampu menafsirkan makna aljabar notasi (simbol dan tandatanda) baik; (2) pemahaman notasi algberaic pelajaran lisan menengah (SVS): (a) pemahaman tentang simbol termasuk dalam pemahaman yang menerjemahkan (terjemahan), (b) Mengakui simbol tapi belum Mampu memadamkan simbol dan variabel, (c) adalah Mampu menginterpretasikan arti dari aljabar notasi (simbol dan tanda-tanda) baik; (3) pemahaman notasi aljabar dari pelajaran lisan rendah (SVR): (a) pemahaman tentang simbol termasuk dalam pemahaman yang menerjemahkan (terjemahan), (b) Mengakui simbol tapi belum Mampu memadamkan simbol dan variabel, (c) belum mampu menafsirkan makna aljabar notasi (simbol, variabel, dan tanda) dengan baik.

Kata Kunci: Memahami Notasi Aljabar, Aljabar Notasi, Kemampuan Verbal.
\end{abstract}

\begin{abstract}
The purpose of the study is to describe the students' understanding on algebraic notation through abilities. The understanding in this study means the ability to translate (translation), the ability to interpret (interpretation), and the ability to extrapolate (extrapolation). This study is a qualitative
\end{abstract}


research. The subjects of this study are 4 fifth grade students in elementary school, consisted of 2 students with high verbal ability called as high verbal subject (SVT), 1 student with medium verbal subject (SVS), and 1 student with low verbal subject (SVR). The focus of this research is to describe the students' understanding on algebraic notation based on their verbal abilities in translation, interpretation, and extrapolation. The data were collected by conducting test-based interview to the research subjects. The research dara were validated by conducting triangulation method, namely interview using major questions as the questions stated in TPNA. Research data were analyzed by (a) studying the subject data and comparing interviewed data to obtain the valid one, (b) conducting data reduction by making the abstraction, (c) classifying and identifying the data to draw the conclusion. The results of the study reveals that (1) the understanding of algebraic notation of high verbal subject (SVT): (a) understanding of the symbols included in the comprehension translate (translation), (b) understand the concept of the symbol but Blum was able to distinguish between symbols and variables, (c) able to interpret the meaning of algebraic notation (symbols and signs) well; (2) the understanding of algebraic notation of medium verbal subject (SVS): (a) understanding of the symbols included in the comprehension translate (translation), (b) recognize symbols but have not been able to distinguish the symbols and variables, (c) is able to interpret the meaning of the notation algebra (symbols and signs) well; (3) the understanding of algebraic notation of low verbal subject (SVR): (a) understanding of the symbols included in the comprehension translate (translation), (b) recognize symbols but have not been able to distinguish the symbols and variables, (c) has not been able to interpret the meaning of algebraic notation (symbol, variable, and marks) well.

Keyword: Understanding the Algebraic Notation, Algebraic Notation, Verbal Ability.

\section{Pendahuluan}

Matematika merupakan salah satu bidang studi yang ada pada semua jenjang pendidikan, mulai dari tingkat sekolah dasar hingga perguruan tinggi. Mata pelajaran matematika dalam setiap jenjang pendidikan formal dipandang memiliki peranan yang sangat penting dalam upaya pembentukan sumber daya manusia yang berkualitas. Salah satu dari tujuan pengajaran matematika yang termuat dalam kurikulum tingkat satuan pendidikan matematika SD adalah menumbuhkan dan mengembangkan keterampilan berhitung (menggunakan bilangan) sebagai alat dalam kehidupan sehari-hari. Dalam berhitung, pemahaman akan nilai tempat adalah sesuatu yang sangat penting karena dalam sistem bilangan yang digunakan sekarang, yaitu sistem bilangan Hindu Arab, suatu bilangan ditentukan nilainya oleh urutan atau posisi suatu angka diantara angka lainnya.

Konsep nilai tempat merupakan konsep dasar yang harus dikuasai oleh siswa di SD. McCloskey dalam Chan, Au, dan Tang (2014) menyatakan bahwa seseorang yang mengalami kesulitan dengan konsep nilai tempat sangat mungkin melakukan kesalahan dalam menyebutkan (membaca) dan menuliskan bilangan multidigit.

Menurut Nurmawati dalam Matitaputty, Putri, dan Hartono (2013), siswa sering salah dalam menuliskan lambang bilangan dan nama bilangan, kekeliruan terjadi ketika siswa menentukan nilai tempat dan nilai angka, dan kesalahan menuliskan lambang bilangan berdasarkan nilai tempat. 
Kesalahan ini mungkin terjadi karena siswa mengalami kesulitan dalam memahami konsep nilai tempat. Sebuah contoh kesalahan penulisan bilangan multidigit diberikan oleh Ginsburg dalam Chan, Au, dan Tang (2014) yaitu menuliskan bilangan seribu dua ratus lima dengan 10002005. Fuson dalam Chan, Au, dan Tang (2014) menambahkan bahwa prosedur-prosedur yang melibatkan struktur bilangan basis sepuluh seperti menyimpan dalam penjumlahan dan meminjam dalam pengurangan juga cenderung menjadi kesalahan.

Berdasarkan hasil observasi yang dilakukan peneliti pada siswa kelas III Sekolah Dasar Negeri 133 Takalala, terlihat bahwa siswa kurang memahami dan memaknai nilai tempat sebuah angka. Kurangnya pemahaman siswa terlihat saat siswa diperlihatkan lambang bilangan lima ratus lima (505) dan diminta untuk menyebutkan posisi dari setiap angka 5 pada bilangan tersebut, ada beberapa jawaban berbeda yang diberikan oleh siswa. Pertama, ada siswa yang mampu menjawab dengan benar bahwa angka lima pada posisi yang paling kanan adalah satuan dan yang paling kiri ada ratusan. Kedua, ada siswa yang menjawab bahwa yang paling kiri adalah puluhan sedangkan yang paling kanan adalah satuan. Ketiga, bahkan ada siswa yang menjawab angka yang paling kiri adalah satuan. Alternatif jawaban kedua dan ketiga ini menunjukkan bahwa siswa masih kurang memahami materi nilai tempat, padahal materi nilai tempat merupakan pondasi untuk mempelajari matematika lebih lanjut.

Menurut Ho dan Cheng (1997), konsep nilai tempat sangat penting dalam pembelajaran matematika khususnya dalam penguasaan aritmatika. Di tingkat awal, kurangnya pemahaman konsep nilai tempat akan menyebabkan rendahnya kemampuan dalam penjumlahan dan pengurangan maupun masalah-masalah aritmatika yang lebih kompleks. Hasil penelitian menunjukkan bahwa secara signifikan skor pemahaman nilai tempat berkorelasi dengan skor penjumlahan dan pengurangan bahkan setelah variabel IQ dikontrol. Ho dan Cheng (1997) menyimpulkan bahwa pemahaman nilai tempat dapat dianggap sebagai prasayarat penting dalam mengembangkan kemampuan penjumlahan.

Pendapat Ho dan Cheng (1997) telah didukung oleh Rosnawati (2013) yang mengungkapkan bahwa profil kemampuan matematika siswa Indonesia dalam benchmark internasional masih berada pada level rendah. Hal itu terlihat dari rendahnya presentase siswa Indonesia yang menjawab soal pada TIMSS 2011 yang mengukur domain kognitif pada level yang paling bawah yaitu pengetahuan yang terkait dengan domain konten bilangan. Diungkapkan oleh Rosnawati (2013) bahwa rendahnya presentasi siswa yang menjawab soal tersebut disebabkan karena pemahaman nilai tempat yang masih belum baik. Pemahaman yang keliru pada nilai tempat akan mengakibatkan kekeliruan dalam operasi penjumlahan. 
Sebuah alat untuk mengukur pemahaman konsep nilai tempat siswa telah dikembangkan oleh Chan, Au, dan Tang (2014). Alat tersebut diberi nama Strategic Counting. Strategic Counting ini dikembangkan berdasarkan Model UDSSI yang menggambarkan urutan perkembangan struktur konseptual bilangan. Setiap tahapan perkembangannya dipetakan pada sebuah cara menghitung.

Strategic counting menawarkan sebuah cara baru dan lebih baik dalam mengukur pemahaman nilai tempat siswa. Dari hasil penelitian yang dilakukan oleh Chan, $\mathrm{Au}$, dan Tang (2014) diungkapkan bahwa strategi menghitung siswa merefleksikan pengetahuan nilai tempat mereka. Siswa yang menggunakan strategi menghitung yang lebih maju juga mengerjakan berbagai tugas numerik dengan lebih baik.

Suherman (1993:134) mengemukakan bahwa matematika sekolah merupakan bagian matematika yang diberikan untuk dipelajari oleh siswa sekolah (formal), yaitu SD, SLTP, dan SLTA. Menurut Soedjadi (2000), matematika sekolah adalah unsur-unsur atau bagian-bagian dari matematika yang dipilih berdasarkan atau berorientasi kepada kepentingan kependidikan dan perkembangan IPTEK. Dengan demikian dapat disimpulkan bahwa matematika sekolah adalah matematika yang telah dipilah-pilah dan disesuaikan dengan tahap perkembangan intelektual siswa, serta digunakan sebagai salah satu sarana untuk mengembangkan kemampuan berpikir bagi para siswa.
Dalam belajar matematika sekolah, seseorang dituntut untuk mampu mencapai apa yang menjadi tujuan pengajaran sesuai dengan fungsi matematika dan taraf kognitif siswa. Pada standar isi mata pelajaran matematika untuk semua jenjang pendidikan dasar dan menengah dinyatakan bahwa tujuan mata pelajaran matematika di sekolah adalah agar siswa mampu:

1. Memahami konsep matematika, menjelaskan keterkaitan antarkonsep dan mengaplikasikan konsep atau algoritma, secara luwes, akurat, efisien, dan tepat dalam pemecahan masalah;

2. Menggunakan penalaran pada pola dan sifat, melakukan manipulasi matematika dalam membuat generalisasi, menyusun bukti, atau menjelaskan gagasan dan pernyataan matematika;

3. Memecahkan masalah yang meliputi kemampuan memahami masalah, merancang model matematika, menyelesaikan model, dan menafsirkan solusi yang diperoleh;

4. Mengkomunikasikan gagasan dengan simbol, tabel, diagram, atau media lain untuk memperjelas keadaan atau masalah; dan

5. Memiliki sikap menghargai kegunaan matematika dalam kehidupan, yaitu memiliki rasa ingin tahu, perhatian, dan minat dalam mempelajari matematika, 
serta sikap ulet dan percaya diri dalam pemecahan masalah.

Sedangkan National Council of Teachers of Mathematics (NCTM) (Kersaint, dkk, 2009) juga telah menetapkan "five goals for all students in Curriculum and and Evaluation Standards for School Mathematics" yakni: (1) that they learn to value mathematics; (2) that they become confident in their ability to do mathematics; (3) that they become mathematical problem solvers; (4) that they learn to communicate mathematically; and (5) that they learn to reason mathematically.

Kilpatrick, Swafford, dan Findell (Afrilianto, 2012) menyatakan bahwa pemahaman konsep adalah salah satu kecapakan matematis yang harus dikuasai oleh siswa dalam pembelajaran matematika. Menurut Afrilianto (2012), pemahaman konsep dan stategis matematis menentukan keberhasilan belajar siswa. Oleh karena itu, pemahaman konsep sangat penting.

Belajar konsep merupakan salah satu cara belajar dengan pemahaman dan kerap dikenal dengan nama "concept formation". Pembelajaran yang mengarah pada upaya pemberian pemahaman pada siswa adalah pembelajaran yang mengarahkan siswa memahami apa yang mereka pelajari, tahu kapan, di mana, dan bagaimana menggunakannya. Pemahaman berbeda dengan hapalan. Keefektifan pembelajaran sangat ditentukan oleh ada tidaknya proses pemahaman atau memahami pengetahuan.
Menurut Wang dan Gafurov (2010), comprehension adalah kemampuan untuk memahami makna sebuah konsep atau tindakan berdasarkan daya cerdas dalam penalaran dan berpikir abstrak. Pemahaman adalah proses kognitif yang lebih tinggi pada otak yang mencari hubungan antara konsep-konsep yang diberikan dan serangkaian atribut (A), objek (O), dan relasi (R) pada memori jangka panjang. Sementara Susanto (2013) menyebutkan bahwa pemahaman adalah suatu proses mental terjadinya adaptasi dan transformasi ilmu pengetahuan.

Untuk memahami, menurut Bloom dalam Susanto (2013), siswa harus melakukan lima tahapan berikut, yaitu: 1) Receiving; 2) Responding; 3) Valuing, 4) Organizing; and 5) Characterization.

Ruseffendi (Susanto, 2013) menyatakan tiga macam pemahaman matematis, yaitu: pengubahan (translation), pemberian arti (interpretation), pembuatan ekstrapolasi (extrapolation). Pemahaman translasi digunakan untuk menyampaikan informasi dengan bahasa dan bentuk lain yang menyangkut pemberian makna dari suatu informasi yang bervariasi misalnya, mampu mengubah soal kata-kata ke dalam simbol dan sebaliknya. Interpolasi digunakan untuk menafsirkan maksud dari bacaan, tidak hanya dengan kata-kata dan frasa, tetapi juga mencakup pemahaman informasi dari sebuah ide, misalnya mampu mengartikan suatu kesamaan. Adapun ekstrapolasi mencakup estimasi dan prediksi yang didasarkan pada sebuah pemikiran, gambaran dari suatu informasi, juga mencakup pembuatan kesimpulan dengan konsekuensi yang sesuai dengan informasi jenjang kognitif yang ketiga yaitu 
penerapan yang menggunakan suatu bahan yang sudah dipelajari ke dalam situasi baru, yaitu berupa ide, teori, atau petunjuk teknis.

Nilai tempat merupakan konsep matematika yang fundamental untuk mempelajari matematika lebih lanjut. Pengertian nilai tempat berdasarkan Mathematics in The New Zealand Curriculum dalam Matitaputy, Putri, dan Hartono (2013) adalah nilai yang diberikan untuk sebuah angka berdasarkan letak angka tersebut.

Fuson (1997) menyatakan bahwa pemahaman nilai tempat adalah pondasi untuk memahami sistem bilangan dan mengembangakan prosedur penjumlahan dan pengurangan bilangan multidigit, akan tetapi pengembangannya membutuhkan waktu yang lama. Oleh karena itu, nilai tempat harus memiliki posisi yang jelas dalam kurikulum matematika karena nilai tempat memungkinkan siswa untuk memahami ide-ide matematika yang lain.

The Common Core State Standars for Mathematics (CCSM) dalam Thouless (2014) menjelaskan bahwa konsep nilai tempat berkembang secara bertahap mulai dari taman kanak-kanak hingga kelas 6 sekolah dasar. Pada awalnya, siswa berfokus pada penggunaan keteraturan sistem bilangan untuk membantu mereka menghitung. kemudian siswa belajar menyusun dan menguraikan bilangan, mengembangkan ide bahwa ada sepuluh satuan dalam puluhan, ada sepuluh puluhan dalam ratusan, dan angka-angka dalam bilangan dua digit merepresentasikan bilangan puluhan dan satuan secara berurutan. Siswa juga belajar menggunakan pemahaman nilai tempat untuk membantu menyelesaikan operasi-operasi pada bilangan multidigit. Di kelas 2, siswa memperluas pengetahuan tersebut meliputi ide bahwa ada sepuluh ratusan dalam ribuan dan angka-angka dalam bilangan tiga angka secara berurutan mewakili bilangan ratusan, puluhan, dan satuan. Di akhir kelas 3, siswa diharapkan dapat menjumlah dan mengurangi hingga 1000 dan di akhir kelas 4, siswa diharapkan menerapkan pemahaman nilai tempat mereka hingga jutaan. Sementara siswa di kelas 5 mengembangkan pengetahuan mereka hingga bilangan desimal, dan siswa di kelas 6 mengembangkan pengetahuan mereka hingga bilangan negatif.

Kemampuan awal (Entry Behavior) adalah kemampuan yang telah diperoleh siswa sebelum dia memperoleh kemampuan terminal tertentu yang baru. Kemampuan awal menunjukkan status pengetahuan dan keterampilan siswa sekarang untuk menuju ke status yang akan datang yang diinginkan guru agar tercapai oleh siswa. Dengan kemampuan ini dapat ditentukan dari mana pengajaran harus dimulai. Kemampuan terminal merupakan arah tujuan pengajaran diakhiri. Jadi, pengajaran berlangsung dari kemampuan awal sampai ke kemampuan terminal itulah yang menjadi tanggung jawab pengajar (Multazam Ahmad, 2013).

Identifikasi kemampuan awal dan karakteristik peserta didik adalah salah satu upaya para guru yang dilakukan untuk memperoleh pemahaman tentang; tuntutan, bakat, minat, kebutuhan dan kepentingan peserta didik, berkaitan dengan suatu program pembelajaran tertentu. Tahapan ini dipandang begitu perlu mengingat banyak pertimbangan seperti; peserta didik, perkembangan sosial, budaya, ekonomi, ilmu pengetahuan dan teknologi, serta kepentingan program pendidikan/ 
pembelajaran tertentu yang akan diikuti peserta didik.

Identifikasi kemampuan awal peserta didik bertujuan:

1. Memperoleh informasi yang lengkap dan akurat berkenaan dengan kemampuan serta karakteristik awal siswa sebelum mengikuti program pembelajaran tertentu.

2. Menyeleksi tuntutan, bakat, minat, kemampuan, serta kecenderungan peserta didik berkaitan dengan pemilihan program-program pembelajaran tertentu yang akan diikuti mereka.

3. Menentukan desain program pembelajaran dan atau pelatihan tertentu yang perlu dikembangkan sesuai dengan kemampuan awal peserta didik. (Multazam Ahmad, 2013)

\section{Metode}

Penelitian ini adalah penelitian deskriptif-eksploratif dengan pendekatan kualitatif yang bertujuan mengamati bagaimana profil pemahaman nilai tempat melalui strategic counting pada siswa kelas III SDN 133 Takalala. Instrumen dalam penelitian ini peneliti sendiri sebagai instrument utama yang dipandu dengan tes kemampuan matematika awal matematika (TKAM), strategic counting (SC), dan pedoman wawancara. Subjek penelitian ini adalah siswa kelas III Sekolah Dasar yang terdiri dari 3 kelompok yaitu 2 orang siswa yang memiliki kemampuan awal tinggi, 2 siswa yang berkemampuan awal sedang dan 2 orang siswa yang berkemampuan awal rendah.
Adapun langkah-langkah pemilihan subjek dalam penelitian ini adalah sebagai berikut.

1. Memberikan tes kemampuan awal matematika. Langkah ini bertujuan untuk mengidentifikasi kategori kemampuan awal matematika siswa (kemampuan awal matematika tinggi, sedang dan rendah).

2. Menganalisis skor tes kemampuan awal matematika setiap siswa. Hasil analisis yang diperoleh menunjukkan bahwa siswa memiliki kemampuan awal matematika tinggi, sedang atau rendah. Adapun pengelompokan siswa dalam tiga kategori kemampuan awal matematika dilakukan berdasarkan kriteria penilaian berikut:

Tabel 1.

Kategori Kemampuan Awal Matematika Siswa

Kemampuan Matematika Siswa

Tinggi $\quad$ Skor tes $\geq 80$

Sedang $\quad 65<$ Skor tes $<80$

Rendah $\quad$ Skor tes $\leq 65$

(Sumber: Profil pemahaman siswa terhadap simbol, huruf, dan tanda pada aljabar ditinjau dari kemampuan matematika siswa dan fungsi kognitif rigorous mathematical thinking (RMT) oleh Sujalmo dan Budiarto).

3. Memberikan tes pemahaman nilai tempat pada kelas III untuk mendiagnosis gambaran pemahaman siswa terhadap nilai tempat. Tes pemahaman nilai tempat yang digunakan dalam penelitian ini adalah Strategic Counting. 
4. Memilih minimal satu subjek dari setiap kategori. Subjek dipilih dengan mengkonsultasikan kepada guru dengan pertimbangan: (1) Siswa tersebut telah mendapatkan materi nilai tempat, (2) Mampu mengkomunikasikan pemikirannya secara lisan maupun tulisan dengan baik, (3) Kesediaan subjek untuk berpartisipasi dalam pengambilan data selama penelitian.

\section{Hasil dan Pembahasan}

Berdasarkan data yang diperoleh, terdapat 6 siswa yang memiliki kemampuan awal tinggi, 7 siswa yang memiliki kemampuan awal sedang, dan 9 siswa yang memiliki kemampuan awal rendah.

Karena calon subjek yang memenuhi kriteria lebih dari satu, maka subjek dipilih berdasarkan pertimbangan guru dengan acuan: (1) subjek dapat berkomunikasi/mengekspresikan

pikirannya berdasarkan pengamatan guru selama proses belajar terjadi dikelas; (2) Kesedian subjek untuk berpartisipasi dalam pengambilan data selama penelitian dan mampu berkomunikasi dengan jelas. Maka calon subjek yang terpilih dijadikan subjek dalam penelitian ini, adapun calon subyek dalam penelitian ini adalah ST(01), ST(02), SS (01), SS(02), SR (01), SR (02).

Tabel 2.

Profil Pemahaman Konsep Nilai Tempat Subjek Berkemampuan Awal Matematika Tinggi

\begin{tabular}{|c|c|c|c|}
\hline Soal & ST-01 & \multicolumn{2}{|c|}{ ST-02 } \\
\hline 1 & 13 kotak kecil, & 13 kotak kecil & Pada soal bilangan dua digit, soal nomor 1 , strategic counting \\
\hline 2 & 42 kotak kecil & 42 kotak kecil & ST-01 yaitu dengan cara menghitung satu persatu (count all) \\
\hline 3 & 54 kotak kecil & 54 kotak kecil & sedangkan ST-02 yaitu dengan cara menghitung puluhan \\
\hline 4 & 22 kotak kecil & 22 kotak kecil & kemudian satuan lalu menjumlahkan. Pada soal nomor 2-5 \\
\hline 5 & 33 kotak kecil & 33 kotak kecil & strategic counting ST-01 sama dengan strategic counting pada \\
\hline 6 & 124 kotak kecil & 124 kotak kecil & ST-02 yaitu dengan cara menghitung puluhan terlebih dahulu \\
\hline 7 & 403 kotak kecil & 403 kotak kecil & kemudian menghitung satuan lalu menjumlahkan. \\
\hline 8 & 526 kotak kecil & 526 kotak kecil & Pada soal bilangan tiga digit, soal nomor $6-10$ strategic \\
\hline 9 & 324 kotak kecil & 324 kotak kecil & counting ST-01 sama dengan strategic counting pada ST-02 \\
\hline 10 & 234 kotak kecil & 234 kotak kecil & $\begin{array}{l}\text { yaitu dengan cara menghitung ratusan terlebih dahulu } \\
\text { kemudian menghitung puluhan lalu satuan kemudian } \\
\text { dijumlahkan. }\end{array}$ \\
\hline
\end{tabular}

Tabel 3.

Profil Pemahaman Konsep Nilai Tempat Subjek Berkemampuan Awal Matematika Sedang

\begin{tabular}{cccl}
\hline Soal & ST-01 & ST-02 & \multicolumn{1}{c}{ Ket } \\
\hline 1 & 13 & 13 kotak kecil & Pada soal bilangan dua digit, soal nomor 1, strategic counting \\
2 & 42 & 42 kotak kecil & SS-01 dan SS-02 sama-sama dengan cara menghitung satu \\
3 & 54 & 54 kotak kecil & persatu (count all). Pada soal nomor 2-5 strategic counting SS- \\
4 & 22 & 22 kotak kecil & 01 sama dengan strategic counting pada SS-02 yaitu dengan \\
5 & 33 & 33 kotak kecil & cara menghitung puluhan terlebih dahulu kemudian \\
6 & 124 & 124 kotak kecil & menghitung satuan lalu menjumlahkan. \\
7 & 403 & 403 kotak kecil & Pada soal bilangan tiga digit, soal nomor 6-10 strategic \\
8 & 526 & 526 kotak kecil & counting SS-01 sama dengan strategic counting pada SS-02
\end{tabular}


$9 \quad 324$

$10 \quad 234$
324 kotak kecil

234 kotak kecil yaitu dengan cara menghitung ratusan terlebih dahulu kemudian menghitung puluhan lalu satuan kemudian dijumlahkan.

Tabel 4.

Profil Pemahaman Konsep Nilai Tempat Subjek Berkemampuan Awal Matematika Rendah

\begin{tabular}{clll}
\hline Soal & ST-01 & ST-02 & Ket \\
\hline 1 & 13 & 13 & Pada soal bilangan dua digit, soal nomor 1, strategic counting \\
2 & 42 & 46 & SS-01 dan SS-02 sama-sama dengan cara menghitung satu \\
3 & 54 & 53 & persatu (count all). Pada soal nomor 2-5 strategic counting SS- \\
4 & 22 & 22 & O1 sama dengan strategic counting pada SS-02 yaitu dengan \\
5 & 33 & 33 & cara menghitung puluhan terlebih dahulu kemudian \\
6 & 124 & 124 & menghitung satuan lalu menjumlahkan. \\
7 & 403 & 403 & Pada soal bilangan tiga digit, soal nomor 6-10 strategic \\
8 & 526 & 526 & counting SS-01 sama dengan strategic counting pada SS-02 \\
9 & 324 & 324 & yaitu dengan cara menghitung ratusan terlebih dahulu \\
10 & 234 & 234 & kemudian menghitung puluhan lalu satuan kemudian
\end{tabular}

Berdasarkan paparan data sebelumnya bahwa terdapat 6 siswa yang memiliki kemampuan awal matematika tinggi setelah diberikan tes kemampuan awal, sehingga untuk memperoleh data yang lebih mendalam maka dipilih 2 subjek yang memenuhi kriteria untuk di wawancara. Merujuk dari teori yang dikemukakan oleh Bano Ekaningsih (2012), Kemampuan awal siswa adalah salah satu faktor dari aspek pribadi siswa juga merupakan hal yang penting dalam proses belajar mengajar. Kemampuan awal merupakan prasyarat yang diperlukan oleh siswa dalam mengikuti proses belajar mengajar.

Setelah diberikan tes kemampuan awal matematika terdapat 8 siswa yang berkemampuan awal matematika sedang. Pemahaman konsep nilai tempat pada kelompok kemampuan awal sedang tidak jauh berbeda dengan pemahaman nilai tempat pada kelompok kemampuan awal matematika tinggi. Pada kelompok kemampuan awal matematika sedang terdapat 2 jenis jawaban yang diberikan subjek dalam memahami konsep nilai tempat. Ada kelompok subjek yang memberikan jawaban tanpa disertai keterangan ratusan, puluhan dan satuan dan terdapat kelompok subjek yang memberikan jawaban dengan disertai keterangan ratusan, puluhan dan satuan walaupun masih terdapat jawaban keterangan yang salah.

Setelah diberikan tes kemampuan awal matematika terdapat 9 siswa yang berkemampuan awal rendah. Pada kemampuan awal rendah ditemukan hanya satu jenis jawaban pemahaman konsep nilai tempat, subjek dominan menghitung secara satu persatu soal-soal yang diberikan dan jawaban yang diberikan masih terdapat kekeliruan di dalamnya. Subjek belum memiliki strategic counting yang bervariasi sesuai dengan strategic counting yang seharusnya digunakan, subjek rendah hanya memiliki 1 strategic counting yaitu menghitung secara satu persatu. Jadi ketika siswa di 
arahkan kepada soal yang jumlahnya ratusan subjek kewalahan dalam menghitung karena harus menghitung satu persatu kotak-kotak satuan yang jumlahnya ratusan.

\section{Penutup}

Penutup ditulis untuk mengarahkan pembaca mendapatkan hal-hal penting yang tidak dangkal dan sempit. Penutup terdisi dari dua bagian, kesimpulan dan saran. Kesimpulan menyajikan ringkasan dari uraian mengenai hasil dan pembahasan, mengacu pada tujuan penelitian. Berdasarkan kedua hal tersebut dikembangkan pokok-pokok pikiran baru yang merupakan esensi dari temuan penelitian.

Berdasarkan hasil analisis pada Bab IV, maka dapat disimpulkan sebagai berikut:

1. Pemahaman Subjek Kemampuan Awal Matematika Tinggi (ST) :

a. Mengenal dan mampu memaknai konsep nilai tempat (ratusan, puluhan dan satuan)

b. Memiliki strategic counting yang bervariasi sesuai dengan tingkatan soal.

$$
\begin{aligned}
& \text { c. Mampu memberikan } \\
& \text { interpretasi konsep nilai } \\
& \text { tempat khususnya ratusan, } \\
& \text { puluhan dan satuan dengan } \\
& \text { menggunakan kotak-kotak } \\
& \text { satuan. }
\end{aligned}
$$

2. Pemahaman Subjek Kemampuan Awal Matematika Sedang (SS) : a. Mengenal dan mampu memaknai konsep nilai tempat (ratusan, puluhan dan satuan)

b. Memiliki strategic counting yang bervariasi akan tetapi terkadang tidak konsisten dalam menggunakan strategic counting.
c. Mampu memberikan interpretasi konsep nilai tempat khususnya ratusan, puluhan dan satuan dengan menggunakan kotak-kotak satuan

3. Pemahaman Subjek Kemampuan Awal Matematika Rendah (SR):

a. Mengenal konsep nilai tempat (ratusan, puluhan dan satuan) akan tetapi belum mampu memaknai konsep nilai tempat

b. Hanya memiliki satu strategic counting yaitu dengan cara menghitung satu-persatu kotak satuan atau count all.

c. Belum mampu memberikan interpretasi konsep nilai tempat khususnya ratusan, puluhan dan satuan dengan menggunakan kotak-kotak satuan.

\section{Daftar Pustaka}

Afrilianto, M. 2012. Peningkatan Pemahaman Konsep dan Kompetensi Strategis Matematis Siswa SMP dengan Pendekatan Metaphorical Thingking. Infinity Jurnal Ilmiah Program Studi Matematika STIKIP 
Siliwangi Bandung, Vol 1, No.2, September 2012.

Brown, P., Evan, M., Hunt, D., McIntosh, J., Pender, B., Ramagge, J. 2011. Counting and Place Value. AMSI.

Budi, T.S. 2010. Peningkatan Kemampuan Memahami Nilai Tempat dengan Media Abacus pada Siswa Kelas II SD Negeri Bukuran 2 Kecamatan Kalijambe Kabupaten Sragen TP 2009/2010. Skripsi. Universitas Sebelas Maret Surakarta.

Chan, W.W.L., Au, T.K., Tang, J. 2014. Strategic Counting: A Novel Assessment of Place-Value Understanding. Learning and instruction, 29, 78-94. http://dx.doi.org/10.1016/j.learninstru c.2013.09.001.

Cooper, L.L., \& Tomayko, M.C. 2011. Exploring Ancient Numbers Helps Students Focus on the Structure and Properties of Our Hindu-Arabic System. NCTM.

Depdikbud. 1993. Kurikulum 1994 Sekolah Dasar. Jakarta: Depdikbud

Depdiknas. 2005. Undang-Undang Sisdiknas 2003 (UU RI No. 20 tahun 2003). Jakarta: Sinar Grafika.

EII, F. (2001). Strategies and thinking about number in children aged 9-11. Technical Report 17, University of Auckland, Auckland, NZ.

Fuson, K. C., Wearne, D., Hiebert, J., Murray, H. G., Human, P. G., Olivier, A. I., et al. (1997). Children's conceptual structures for multidigit numbers and methods of multidigit addition and subtraction. Journal of Research in Mathematics Education, 28, 130e162.

Ho, C. S. H., \& Cheng, F. S. F. (1997). Training in place-value concepts improves children's addition skills. Contemporary Educational Psychology, 22, 495e506. http://dx.doi.org/10.1006/ceps.1997. 0947.

Kersaint, G., Thompson, D. R., \& Petkova, M. 2009. Teaching Mathematics to English Language Learners. New York: Routledge.

Matitaputty, C., Indra P.R.I., and Hartono, Y. (2013) Pembelajaran Nilai Tempat Menggunakan Kegitan Bertukar Biota Laut Kelas II Sekolah Dasar. EDUMAT Jurnal Edukasi Matematika, 4 (7). pp. 439-450. ISSN 2087-0523

McGuire, P., Kinzie, M.B., Kilday, C.R., \& Whittaker, J.E.V. 2010. Children's Understanding of Two-Digit Place Value: A Place for Place Value in Pre-K. University of Virginia.

Price, P.S. 2001. The Development of Year 3 Students' Place-Value Understanding: Representations and Concepts. Queensland University of Technology.

Puskur. (2002). Kurikulum dan Hasil Belajar: Kompetensi Dasar Mata Pelajaran Matematika Sekolah Dasar dan Madrasah Ibtidaiyah. Jakarta: Balitbang Widyantini.

Rafianti, Isna (2013) Penerapan Model Pembelajaran Matematika Berbasis Multiple Intelligences untuk Meningkatkan Kemampuan 
Pemahaman Konsep, Penalaran Matematis dan Self-Confidence Siswa MTs. S2 thesis, Universitas Pendidikan Indonesia.

Resnick, L. (1983). A developmental theory of number understanding. In $\mathrm{H}$. Ginsburg (Ed.), The development of mathematical thinking (pp. 109e151). London: Academic Press.

Rosmawati, R. 2013. Kemampuan Penalaran Matematika Siswa SMP pada TIMSS 2011. (Online). Diakses dari: (http://staff.uny.ac.id/ sites/default/files/penelitian/R.\%20Ro snawati,\%20Dra.\%20M.Si./Makalah\%2 OSemnas\%202013\%20an\%20R\%20Ro snawati\%20FMIPA\%20UNY.pdf.)

Sabri. 2011. Diagram V: Perangkat Metakognisi untuk Penyelesaian Masalah Matematika. Makassar: Universitas Negeri Makassar.

Skemp, R. 1987. The Psychology of Learning Mathematics. Expanded American Edition. New Jersey: Lawrence Elbaum Associates. Publishers.

Skemp, R. 2005. Relational Understanding and Instrumental Understanding. http://www.blog.republicofmath.com Larchives/654. Diakses, 18 November 2011.

Soedjadi. 2000. Kiat Pendidikan Matematika di Indonesia. Jakarta: Direktorat Jendral Pendidikan Tinggi Departemen Pendidikan Nasional.

Suherman, Erman. 1993. Evaluasi Proses dan Hasil Belajar Matematika. Jakarta: Universitas Terbuka. Depdikbud.
Sugiyono, 2009. Metode Penelitian Pendidikan, Pendekatan Kuantitatif, Kualitatif, dan $R$ \& D. Bandung: Alfabeta.

Sujalmo, N dan Budiarto, M.T. 2013. Profil pemahaman siswa terhadap simbol, huruf, dan tanda pada aljabar ditinjau dari kemampuan matematika siswa dan fungsi kognitif rigorous mathematical thingking (RMC). http://ejournal.unesa.ac.id/index.php/ mathedunesa/article/view/3892.

Susanto, Ahmad. 2013. Teori Belajar \& Pembelajaran di Sekolah Dasar. Jakarta: Kencana.

Thouless, H.R. 2014. Whole Number PlaceValue Understanding of Students with Learning Disabilities. Unpublished Dissertation. Washington: University of Washington.

Usman, R. 2013. Meningkatkan Pemahaman Konsep Nilai Tempat Melalui Metode Bermain Pada Siswa Kelas II SDN 1 Molui Kecamatan Kwadang Kabupatern Gorontalo Utara. Skripsi. Universitas Negeri Gorontalo.

Wang, Y. and D. Gafurov (2010), The Cognitive Process of Comprehension: A Formal Description, International Journal of Cognitive Informatics and Natural Intelligence, 4(3), 44-58. 